\title{
ROSA LUXEMBUURG: LA REVOLUCIÓN EL ÚNICO CAMINO
}

\author{
ROSA LUXEMBURG: THE REVOLUTION THE ONLY WAY \\ (iD) Susana Bruno Ochoa ${ }^{1 *}$ \\ susanabruno4@gmail.com \\ ${ }^{1}$ Benemérita Universidad Autónoma de Puebla, Zaragoza, México
}

*Correspondencia: Susana Bruno Ochoa. Email: susanabruno4@gmail.com

Recibido: 24.05.19 | Aprobado: 16.06.19

\section{RESUMEN}

Rosa Luxemburg, gran líder, mujer de ideales firmes que consideraba que no había otro camino hacia la libertad que la revolución, fue cofundadora del Partido Comunista de Alemania y defendió sus ideales hasta el día de su brutal muerte en 1919. En 1917 desde la cárcel de Breslau, escribía una carta a su joven amiga Sophie Liebknecht, en dicha carta, hacía patente la esperanza, de que, los proletarios alemanes despertaran a la revolución, para incitar a su joven amiga a mantener "la frente en alto" y conservar la fortaleza, la autora escribió las siguientes líneas: “... ¡Todo cambiará y va a mejorar!, ¡No hay que esperar siempre lo peor! (Schütrumpf 2007, 58).

Palabras clave: Revolución, Rosa Luxemburg

\begin{abstract}
Rosa Luxemburg, a great leader, a woman of firm ideals who believed that there was no other way to freedom than revolution, was a co-founder of the Communist Party of Germany and defended her ideals until the day of her brutal death in 1919. In 1917 from prison from Breslau, wrote a letter to her young friend Sophie Liebknecht, in this letter, she made clear the hope that the German proletarians would wake up to the revolution, to encourage her young friend to keep "her head high" and preserve the strength, the author wrote the following lines: “... Everything will change and it will get better! Don't always expect the worst! (Schutrumpf 2007, 58).
\end{abstract}

Keywords: Revolution, Rosa Luxemburg 
“...El acto más revolucionario siempre consiste en decir la verdad en voz alta...” 1

Rosa Luxemburg

Rosa Luxemburg, gran líder, mujer de ideales firmes que consideraba que no había otro camino hacia la libertad que la revolución, fue cofundadora del Partido Comunista de Alemania y defendió sus ideales hasta el día de su brutal muerte en 1919. En 1917 desde la cárcel de Breslau, escribía una carta a su joven amiga Sophie Liebknecht ${ }^{2}$, en dicha carta, hacía patente la esperanza, de que, los proletarios alemanes despertaran a la revolución, para incitar a su joven amiga a mantener "la frente en alto" y conservar la fortaleza, la autora escribió las siguientes líneas: “... iTodo cambiará y va a mejorar!, ¡No hay que esperar siempre lo peor! (Schütrumpf 2007, 58)

En el pensamiento de Rosa Luxemburg prevalecieron la libertad y la igualdad como dos estafetas que habrían de llevarse a la par dentro del marco de la Revolución. En este trabajo se muestra la lucha que llevó a lo largo de su vida la filósofa polaca, al permanecer fiel al ideal de la revolución, ideal que hace eco a 100 años de su muerte. Rosa es el ejemplo paradigmático de la coherencia entre teoría y praxis ante la adversidad, ya que, cuando en 1906 cayó presa en Varsovia rechazó cualquier intervención diplomática del Reich, “(...) Se mantuvo como Citoyen, es decir, una ciudadana en el sentido de la Revolución Francesa, con autoestima y deseosa de su libertad, en otras palabras, una rareza para Alemania (...)" (Schütrumpf 2007, 23). La libertad es un proyecto que dirigió todos los aspectos de su vida revolucionaria y, por tanto, representa un ideal de lucha abierta que no debe ser abandonado bajo ningún pretexto. Pues la libertad, no está a manos de un frente político, sino que debe ser accesible para todos: “...La libertad sólo para los que apoyan al gobierno, sólo para los miembros de un partido (por numeroso que este sea) no es libertad en absoluto. La libertad es siempre y exclusivamente libertad para el que piensa de manera diferente..." (Luxemburg, La revolución rusa 2006, 400). Para Luxemburg la única forma de alcanzar la libertad es mediante la revolución, por ello, queda anulado cualquier discurso que pretende alcanzarla su cometido "por medio de la reforma legislativa”, ya que, esto carece de realidad y eficiencia.

Rosa Luxemburg tuvo: “(...) Una vida corta, (pero) rica en persecuciones, y corta a causa de una ejecución por quienes se mostraron, la noche de ese 15 de enero, como Rosa Luxemburg ya los había descrito: inhumanos y despiadados (...)" (Schütrumpf 2007, 98)

La producción capitalista tiene diversas características entre ellas destacan tres: 1) existe una separación del productor de medios de producción, 2) la concentración de los medios de producción en la forma de monopolio, en manos de una sola clase social la burguesía y 3) la aparición de una clase social que no tiene otro medio de supervivencia que su propio trabajo, esta clase es el proletariado. La característica principal del proletariado es el estar separado de los medios de producción y no disponer de ingresos

${ }^{1}$ (Schütrumpf 2007, 44)

2 Nació en Rusia en 1884, perteneció al partido socialista alemán (SPD), socialista alemana y feminista. 
suficientes para trabajar por su propia cuenta. Así para la filósofa al igual que para Marx el hombre del proletariado se encuentra en una explotación circular, está deprovisto de los medios de producción y del capital necesario para la inversión, además es oprimido socialmente, ya que, su posición dentro de la sociedad está determinada por su estatuto y el lugar que ocupa en la línea de producción.

Rosa Luxemburg afirmaba que es la clase obrera la que lleva a cabo las transformaciones de la revolución; sin embargo, para que esto sea posible es necesario que se cumplan ciertas condiciones, entre ellas destacan las condiciones históricas, el desarrollo de las instituciones democráticas y la educación de la clase del proletariado:

“(...) Pero para estar a la altura de estas tareas, las masas obreras han de ser sobre todo conscientes de sus deberes y constituirse en masas organizadas según un principio de clase; por otra parte, para que sea posible la implantación de las instituciones socialistas, la sociedad burguesa ha de haber alcanzado previamente un cierto nivel de desarrollo tanto económico como político (...)" (Luxemburg, s.f., 9)

Para Rosa Luxemburg -al igual que para la mayor parte del marxismo- solo la clase del proletariado puede encabezar los ideales de la revolución, por ello, entre los años de 1905 y 1917, Rosa Luxemburg observaba en la Revolución Rusa un proyecto consolidado que podía dirigirse hacia la conquista de la libertad y así representar una lucha que aboliera las clases sociales; sin embargo, dentro del partido socialdemócrata este movimiento tenía sus detractores, entre ellos la facción reformista alemana, la cual, daba una serie de razones por las que la Revolución rusa no era un movimiento revolucionario: 1) No consideraba al proletariado como la base más importante del proyecto revolucionario, ya que, en ese momento la industria rusa no estaba completamente desarrollada, 2) Existía un desconocimiento de la relación que hay entre el poder y la historia, lo que deriva en una separación entre el derrocamiento del gobierno y la lucha de clases, dando preferencia al primero $^{3}$. 3) La Revolución rusa fue local, es decir, olvidó uno de los preceptos fundamentales de Marx: imponer el levantamiento revolucionario mundial. 4) Finalmente, no existe ninguna preocupación por la educación de la clase obrera, ya que supone que al pertenecer a la clase trabajadora se tiene la experiencia necesaria para dirigir la revolución. A pesar de estos tropiezos presentes en la revolución rusa, esta ha demostrado la importancia de las huelgas de masas para combatir las desigualdades entre las clases, ya que, generan un impulso para lucha política. Cabe destacar, que la filósofa desconocía el contexto particular de Rusia, por tanto tenía algunos errores de percepción; sin embargo, su preocupación se centraba en otorgar la importancia histórica de los acontecimientos en torno a esta revolución: “[...] El análisis crítico de la Revolución Rusa con todas sus consecuencias históricas constituye el mejor entrenamiento para la clase obrera alemana e internacional, teniendo en cuenta las tareas que le aguardan como resultado de la situación actual [...]” (Luxemburg, 2006, 379)

Para Rosa Luxemburg, la revolución a manos de la clase del proletariado es un proceso lento y complejo, en el cual intervienen diversos factores para consolidar la 
Dictadura del Proletariado. Para que esto sea posible las condiciones históricas deben ser las adecuadas, es decir, la industria capitalista debe estar completamente desarrollada y las contradicciones entre los intereses de clases deben estar presentes. El llamado de la filósofa polaca es para comprometerse con los ideales revolucionarios, independientemente del estrato social al que se pertenece. Por ello, el deber de la clase del proletariado es hacer un llamado a cuantos más sea posible hacia la lucha: “(...) Según Rosa Luxemburg, formaba parte de la clase trabajadora aquella persona, que se comprometía al interior de la clase trabajadora y con esta en contra de las condiciones imperantes; sin importar su origen o su estado social actual. La praxis, y no el estatus, era su criterio. Entendía a la clase como movimiento (...)" (Schütrumpf 2007, 33)

La preocupación de Rosa Luxemburg por llevar a cabo una revolución paso a paso es patente en su texto Huelgas de masas, partidos y sindicatos, allí expone su preocupación ante el rechazo de algunos dirigentes sindicales hacia la huelga general, pues para ella este rechazo es parte de un discurso de la clase capitalista que teme perder su lugar privilegiado en la sociedad. La autora afirma que las huelgas son un fenómeno interesante, ya que motivan a la educación y al acceso de la información por parte del proletariado. Las luchas económicas instauradas por las huelgas suelen desplegar luchas políticas, si bien la huelga puede ser la antesala de la revolución, esto no siempre sucede debido a la falta de dirección y de un programa de acción de la clase del proletariado: “(...) La voluntad de lucha manifestada por la clase debe fusionarse con la dirección revolucionaria, una dirección que no puede ser improvisada en el curso de la lucha (...)" (Luxemburg, 2003, 13). Para Rosa Luxemburg la huelga, al igual que la revolución, es una forma de lucha de clases que responde a un interés particular de la clase trabajadora y promueve cambios en las relaciones sociales y políticas.

El análisis histórico de las huelgas, que realiza Rosa Luxemburg, hace visible que a través de ellas los trabajadores han conquistado derechos laborales, sociales, políticos y con ello otorgan sentido a su programa revolucionario al fortalecer la lucha y la conciencia de clase. Las huelgas rusas son el ejemplo del despertar de los proletarios y del surgimiento del sentimiento del hartazgo dentro de las filas de los obreros, pues con las huelgas generales surgió la esperanza de romper las cadenas. Las masas proletarias no se consideraban más un simple engranaje del capitalismo, al contrario, se sabían parte de un todo y tenían entre sus manos la responsabilidad de luchar hasta las últimas consecuencias por reestablecer el tejido social:" “(...) Las masas proletarias deben aprender a superar su estadio de simples máquinas muertas que el capitalista aplica al proceso de producción, y convertirse en dirigentes pensantes, libres, protagonistas de esa misma producción social. Deben adquirir el sentimiento de su responsabilidad como miembros de la colectividad, única depositaria de toda la riqueza social (...)" (Luxemburg, s.f., 43). Las huelgas son, para Rosa Luxemburg, un escenario preparatorio para el movimiento revolucionario, al cual solo se puede llegar a través de paulatinas conquistas.

${ }^{4}$ Las huelgas generales rusas guiadas por los diferentes sectores de trabajadores llevadas a cabo entre los años de 1903 a 1907 demuestran las conquistas que ha logrado el proletariado organizado y comprometido; dichas conquistas son el antecedente para la revolución. La revolución requiere entre otras cosas la educación de los proletarios, lo cual es posible por medio de la maduración de la lucha de clase y del propio desenvolvimiento histórico. 
Las huelgas han sido consideradas como fenómenos aislados y repentinos; sin embargo, las huelgas de protesta son la manifestación histórica de la lucha de clases, de hecho, es la forma en la que se hace patente la revolución misma y sus intereses se enfocan en cambiar la situación social y las injusticias que se han fraguado a lo largo de años de dominación ejercida por la clase dominante.

Las huelgas, como lucha política, representan una unidad dialéctica, por esta razón, es posible pasar de una lucha económica a una transformación política. Rosa Luxemburg estaba convencida de que la lucha política educaba a las masas y las mantenía en constante acción, por lo tanto, esta era imprescindible para la revolución. La conciencia de clase no puede aprenderse en la escuela, por tanto, debe educarse en las calles, es decir, la clase del proletariado debe probarse en la lucha, solo así la organización podrá fortalecerse poco a poco.

La filósofa observaba con desagrado la postura de los sindicatos alemanes con respecto a la huelga, ya que aquellos rechazaban los movimientos de masas al considerarlos incendiarios, costosos e innecesarios ${ }^{5}$. Esta postura demostraba una falta del conocimiento de los sucesos históricos que antecedieron a la revolución rusa y así mismo expresaba la incapacidad de algunos partidos y sindicaros de comprender la importancia de la lucha proletaria, ya que, afirman que la revolución puede ser sustituida por las reformas. Rosa Luxemburg, realiza una comparación entre el obrero alemán y el obrero ruso, de ello deriva la conclusión siguiente: A pesar de que el obrero alemán posee mayor grado de educación inculcada por el partido socialdemócrata esta educación es principalmente teórica, la ferviente juventud en el proletariado ruso lo llevó a la acción y es en dicha acción en la que los obreros rusos han sido educados; por ello, en Alemania las huelgas de masas no deben ser rechazadas por el partido socialdemócratas, por el contrario deben ser dirigidas por este.

En conclusión, para la filósofa polaca la huelga de masas es una herramienta muy importante para unificar a la clase trabajadora, impulsándola a la acción. Así mismo, es un instrumento que fortalece la confianza de la propia clase obrera, al hacer patente el alcance de sus fuerzas, en oposición a cualquier acuerdo o reforma manipulado por la burguesía liberal.

Las reformas alemanas en el siglo XX sucedieron de una forma vertiginosa $\mathrm{y}$ favorable para la clase del proletariado, lo cual generó una esperanza de progreso y avance continuo. De estos hechos surgió la obra de Eduard Bernstein Las premisas del socialismo y las tareas de la socialdemocracia; una de sus tesis centrales es considerar que el capitalismo, a través del desarrollo histórico ha cancelado sus contradicciones internas, y por tanto, no se encamina a su destrucción; al contrario, el capitalismo desde el siglo XX ha demostrado que es capaz de recuperarse rápidamente de cualquier crisis económica y al superarla se

\footnotetext{
${ }^{5}$ Los sindicatos alemanes oscilaban entre dos posiciones: la primera era considerar que las huelgas eran movimientos espontáneos que carecían de organización y cuyos intereses se limitaban a aspectos puntuales laborales que no correspondían a los aspectos generales de la revolución; ante esta postura Luxemburg afirma que las huelgas son resultados de procesos históricos complejos y que cada lucha de intereses particulares es en realidad una conquista de la clase del proletariado enfocada hacia el bien común. La segunda postura resalta que la huelga fragmenta al proletariado en diferentes grupos y por lo tanto es un mal sustituto de la revolución, la cual aspira a un carácter general. Para Luxemburg, esta postura pierde de vista que justamente es en la lucha donde los obreros aprenden a hacer la Revolución.
} 
fortalece y estabiliza como modelo económico: “...[Todo el trabajo del sindicato] adquiere una importancia muy diferente; mucho mayor que antes, cuando se abandona la idea de aquel esquema de crisis y la especulación sobre el gran derrumbe económico, y se representa la sociedad, tal como ella se desarrolla..." (Bernstein 1982, 291). Por tanto, la revolución ya no es el camino para alcanzar el socialismo, sino que, debe ser mediante la participación democrática y de las reformas que se logrará alcanzar la libertad e igualdad entre las clases.

Rosa Luxemburg, consideraba que el partido socialista debe tener en cuenta las reformas, sin embargo, estas son parte de la revolución, nunca un sustituto de esta. En ese sentido, la postura de la filósofa era clara: la reforma y la revolución forman parte de un conjunto dialéctico; por tanto, no se trata de elegir esta o aquella, sino que la revolución incluye la lucha por reformas. El error de la postura reformista es considerar que las reformas son un camino "no violento" para lograr la transformación; es decir, existe la pretensión errónea, de que, a través de las reformas se puede permanecer en la sociedad burguesa cumpliendo las aspiraciones socialistas: "[Así Bernstein] Llegó a la conclusión de que la revolución era innecesaria, que se podía llegar al socialismo mediante la reforma gradual del sistema capitalista, a través de mecanismos tales como las cooperativas de consumo, los sindicatos y la extensión gradual de la democracia política [...]" (Luxemburg, 1967, 37)

En el texto Reforma o revolución, la filósofa realiza una aguda crítica al pensamiento reformista que intenta sustituir la revolución, a través de las reformas, bajo el argumento de "la no violencia" que busca conquistar el discurso mostrando una burguesía benevolente y desviar el verdadero fin del proletariado que es alcanzar la libertad: “(...) La lucha por las reformas es su medio; la revolución social, su fin (...)” (Luxemburg, 1967, 9). La dura crítica que Luxemburg, lanza contra Bernstein y sus seguidores, es en relación con la dirección que otorgaron al movimiento revolucionario la cual consistía en salvaguardar los intereses de la pequeña burguesía, y a través, de pequeños cambios mantenían a raya al proletariado.

Además, afirma que es un error creer que, a través de las reformas en las leyes laborales, se puede llegar al resultado de la revolución sin pasar por ella, pues esto sólo perpetúa la escisión de las clases sociales. De hecho, es una falsa creencia que el capitalismo no se dirige hacia una crisis, sino que se acerca a un modelo socialista, por tanto, la revolución es cada vez menos necesaria. Estas consideraciones solo reflejan la impostura política de algunos sindicatos que fingen querer el bien común de los trabajadores, pero que, en realidad, han pactado con las clases altas. Pues si bien, a través de las reformas pareciera que se eliminan las diferencias sociales, en realidad el proyecto reformista no tenía en cuenta la igualdad en relación con lo jurídico, político y económico, debido a que no puede ser lograda por un camino diferente que no sea la revolución.

En síntesis, para la filósofa polaca, las reformas son una parte importante en el proceso revolucionario, sin embargo, no pueden sustituir a la revolución por completo. Las reformas sociales deben ser un medio para mantener la constante lucha por conquistar el poder político; sin embargo, no puede sustituirse la revolución a simples reformas esperando que estas enfríen el fervor de la clase del proletariado. Cuando esto sucede el 
movimiento se encuentra en una postura contraria a la que defiende, pues se espera que las reformas sean simples fugas y consuelos para evitar el movimiento masivo. En ese sentido, todo queda en el mismo sitio, en el cual ha estado durante años, cancelándose con ello el proceso revolucionario por lo que se escapa cualquier oportunidad de conseguir la libertad. Por esta razón, el partido socialdemócrata debería haber aspirado no solo a la reforma y a una redistribución más justa del dinero; sino a la supresión del modo de producción capitalista. ${ }^{6}$

\section{CONCLUSIÓN}

La centralización del Estado y el capitalismo creciente han agotado las posibilidades de constituir formas de interacción, en las cuales se pueda dar una convivencia óptima entre los individuos y su entorno. En la cotidianidad, la forma de producción capitalista permea en todos los ámbitos de la vida de los hombres, por esa razón se dedica cada vez menos tiempo e inversión a aquellas actividades que no entran en el ciclo de la producción capitalista.

Ante esta situación, la única salida es desarrollar un ámbito de convivencia, en el cual la experiencia comunitaria de los individuos permita el cultivo de las habilidades, virtudes y disposiciones para el integral desarrollo de los hombres; con ello el conocimiento de las ciencias humanas no sólo es una posibilidad, sino que, se presenta como una necesidad para lograr adecuadamente la cohesión, la convivencia y la formación de los individuos.

A 100 años de la muerte de Rosa Luxemburg, podemos afirmar que la revolución proletaria es algo posible e inevitable,aunque esta ilusión en la actualidad parece lejana. Por ello, es indispensable estar en constante apropiación de nuevas formas de emancipació, formas en las que la vida de los individuos y las relaciones interpersonales no sean regidas completamente a partir de las leyes del mercado. Solo queda explorar nuevas formas convivencia, incluyendo la expresión creativa, las luchas sociales como las huelgas o las organizaciones comunitarias como el zapatismo o las cooperativas, es decir es importante buscar nuevos modelos organizacionales en la que el hombre no sea explotado hasta el agotamiento.

\section{REFERENCIA BIBLIOGRÁFICA}

Bernstein, Eduard. (1982). Las premisas del socialismo y las tareas de la socialdemocracia. México: Siglo XXI.

Luxemburg, Rosa. (2003). Huelga de masas, partido y sindicato. Madrid: Fundación Federico Engels.

—. La acumulación del capital o en qué han convertido los epígonos la teoría de Marx. Germina, s.f.

Luxemburg, Rosa. «La revolución rusa.» En Obras escogidas, de Rosa Luxemburg, 374406. Izquierda revolucionaria, 2006.

—. Programa de la liga Spartakus y otros escritos. Berlín: Edicions Internacionals Sedov, s.f.

\footnotetext{
${ }^{6}$ Siguiendo a Marx, Rosa Luxemburg está convencida que el modo de distribución del capital está relacionado con el modo de producción. Por lo tanto, apelar a la noción de justicia - tal como la hace Bernstein- en aras de acabar con la desigualdad sin pasar por la revolución es una utopía: "Este es un retorno muy felizmente, por cierto, al viejo caballo de batalla sobre el cual todos los reformadores han cabalgado durante siglos, a falta de medios más seguros. Volvemos al lamentable Rocinante a horcajadas del cual los Don Quijotes de la historia han galopado hacia la gran reforma del mundo, para volver a casa siempre vencidos" (Luxemburg, 1967, 79)
} 
—. Reforma o revolución. Ciudad de México: Grijalbo, S.A., 1967.

Schütrumpf, Jörn. Rosa Luxemburg: o el precio de la libertad. Berlín: Karl Dietz Verlag Berlin, 2007.

\section{CITAR COMO:}

Bruno Ochoa, S. (2019). Rosa Luxemburg: la revolución el único camino. Puriq, 1(01), $25-32$. https://doi.org/10.37073/puriq.1.01.8 